\title{
Religiosidade e Funcionamento Mental em Idosos Portugueses: Uma Perspetiva Sociopsicológica*
}

\author{
Clara Margaça** (D) \& Donizete Rodrigues (D) \\ Universidade da Beira Interior, Covilhã, Portugal
}

\begin{abstract}
RESUMO - $\mathrm{O}$ artigo tem como objetivo analisar a relação entre a religiosidade e o funcionamento mental em idosos portugueses. Os instrumentos metodológicos utilizados foram: um questionário sociodemográfico, a Escala de Orientação Religiosa-R e o Mental Health Inventory (MHI-5). Os resultados da análise mostraram que, embora sem uma relação estatisticamente relevante entre religiosidade e funcionamento mental de uma forma geral, existem, no entanto, diferenças significativas entre a frequência de participação em celebrações religiosas e melhores níveis de funcionamento mental.

PALAVRAS-CHAVE: religiosidade, funcionamento mental, envelhecimento, qualidade de vida
\end{abstract}

\section{Religiosity and Mental Functioning in Portuguese Elderly: A Sociopsychological Perspective}

\begin{abstract}
This article aims to analyze the relationship between religiosity and mental functioning in the elderly Portuguese people. The methodological tools used included the Religious Orientation Scale-R and the Mental Health Inventory (MHI5) and also a socio-demographic questionnaire. The results of the analysis showed that there is no statistically significant relationship between religiosity and mental functioning; however, there are significant differences between the frequency of participation in religious celebrations and better levels of mental functioning.
\end{abstract}

KEYWORDS: religiosity, mental functioning, aging, quality of life

\section{INTRODUÇÃO}

O envelhecimento é uma realidade premente da sociedade portuguesa, resultando em uma pirâmide etária de base estreita e topo alargado, situação presente também em grande parte das sociedades europeias contemporâneas. De acordo com os censos do Instituto Nacional de Estatística (INE), de 2011, para cada 100 jovens há 129 idosos, estando também a diminuir a população ativa, o que se traduz em grandes preocupações sobre como será possível garantir o bem-estar de um importante segmento de uma população cada vez mais envelhecida. Em 1970, Portugal era o país menos envelhecido da Europa e, embora todos os países europeus, de uma maneira geral, tenham envelhecido, Portugal foi o que mais subiu na tabela, se tornando, em 2011, um dos países com maior concentração de pessoas idosas do mundo (INE, 2012). Porém, dados atuais apontam para uma intensificação do processo de envelhecimento demográfico: em 2019, existiam 157,4 idosos para cada 100 jovens (PORDATA, 2020), o que se traduz em 2.280.424 pessoas com 65 anos de idade ou mais.

Apesar de a idade biológica não indicar diretamente quais alterações (e em que grau) surgirão com o avançar da idade, existe a certeza de que o envelhecimento traz incapacidades físicas e cognitivas. O aumento da longevidade se deve sobretudo às transformações sociais, econômicas e de saúde (Dias \& Pais-Ribeiro, 2018), obrigando os profissionais de saúde a se depararem com o desafio de equacionar a qualidade de vida com o objetivo de além de "dar anos à vida, ser necessário dar vida aos anos" (Araújo et al., 2007,

* O referido artigo é baseado na Dissertação de Mestrado da primeira autora.

** E-mail: claramargaca@gmail.com

- Submetido: 21/02/2019; Revisado: 12/03/2020; Aceito: 06/07/2020. 
p. 60). Um envelhecimento com sucesso - que pressupõe um envelhecimento ativo - é conseguido por meio de vários fatores: relações pessoais próximas com familiares e amigos e participação em atividades sociais e produtivas, bem como em atividades de caráter cultural e religioso (Margaça \& Rodrigues, 2016; Rowe \& Kahn, 1998).

Em primeiro lugar, é importante ter em conta que todo estudo relacionado com o envelhecimento, nomeadamente com tudo aquilo que possa contribuir para formas adaptativas de envelhecer, será um grande contributo. Um dos tópicos a ser valorizado é o papel da religiosidade no processo de envelhecimento. Muitos estudos (e.g.: Chaves \& Gil, 2015; Dias \& Pais-Ribeiro, 2018; Pedone, 2019; Queiroz \& Debella, 2016) dos últimos anos associam a religiosidade ao bem-estar, principalmente nos idosos. Em grande medida, isso se deve ao fato de a Organização Mundial de Saúde (OMS) ter introduzido a dimensão espiritual no conceito de saúde, a qual passa a ser caracterizada como bem-estar biopsicossocial e espiritual e não apenas a ausência de enfermidade/doença (OMS, 1998).

As visões mais tradicionais da Psicologia consideravam a religião apenas como um mecanismo de defesa passivo, uma negação idealizada ou como uma forma de 'coping evitante'1; isto é, evitar lidar com os problemas da vida (Pargament \& Ano, 2004). Freud (1907/1961), por exemplo, sugere um paralelo entre as práticas religiosas e as ações obsessivas, acrescentando que tanto as práticas neuróticas como as religiosas serviam de medidas defensivas e de autoproteção envolvidas na repressão dos impulsos instintivos (Lewis, 1994). Freud refere também que qualquer pessoa experimentará um estado de desamparo, abandono, ausência de ajuda e de recursos, aquilo a que o próprio chamou de Hilflosigkeit - vazio. É a partir disso que Freud constata que a religião é o móbil que permite superar a angústia de desproteção pela fé numa onipotência protetora, acabando por reconhecer a religiosidade no ser humano (Freud, 1929/2008). Por outro lado, o conceito de religião, preconizado por Jung, está vinculado à prática dos ritos, exigindo uma postura de escuta, observação e submissão por parte do ser humano à vontade dos deuses; é um equilíbrio entre o eu e o não eu psíquico, ou seja, a religião é vista como função da psique (Xavier, 2006). Segundo Portela (2013), Jung tem a preocupação de estabelecer uma hermenêutica psicológica para a religião, inserindo-a como possibilidade de estudo quando abordada como uma experiência profunda e pessoal (Portela, 2013). Assim, os conteúdos espirituais são compreendidos como fatos, como dados verídicos da experiência psíquica do ser humano.

O sociólogo alemão Georg Simmel (1889/1997) é um autor clássico primordial nessa discussão. Ao contrário de Max Weber, que valoriza a perspetiva comparativa,

1 O "coping evitante" é, normalmente, útil em algumas situações específicas, particularmente as que são de curta duração e incontroláveis. sociológica e histórica, no conceito de religião, Simmel valoriza a lógica da Psicologia, ou seja, a dimensão psicológica. Desta forma, as manifestações e práticas religiosas são mais individuais do que sociais - prevalecem as relações sensoriais do indivíduo, segundo ele. Porém, Simmel chama à atenção que a religião, dada a sua complexidade, é um conceito que ainda não foi possível definir de uma forma precisa, compreensiva e definitiva.

A partir de uma perspetiva estrutural-funcionalista, onde Durkheim (1912/1996) desempenha um papel de relevo, o sociólogo Donizete Rodrigues (2013) preconiza o seguinte conceito de religião: um complexo corpus teóricoteológico sobre a conceção de sagrado e de mundo. É um subsistema cultural estruturado, que integra - ou é composto por - mitos, crenças, com espaços e tempos sagrados, ritos/ rituais, cerimônias, práticas mágicas, doutrinas, dogmas, linguagem, signos e expressões simbólicas, que formam o patrimônio simbólico-religioso e produzem um modelo de relação do(s) indivíduo(s) com o transcendente, com seres sobrenaturais, com uma (ou mais) divindade(s). Conceitualizada de forma diferenciada em cada contexto histórico e sociocultural em que é elaborada (na lógica de Weber, 1997), a religião depende sempre da perspectiva teórica que lhe dá sustentação e do objetivo do estudo.

$\mathrm{O}$ conceito de religiosidade, por sua vez, deriva diretamente do conceito de religião; a religião é a teoria e a religiosidade é a prática. Segundo ainda Rodrigues (2013), religiosidade é uma interpretação própria que um determinado indivíduo ou grupo social faz do corpus teóricoteológico da religião ou da Igreja dominante do qual faz parte. É, na verdade, a forma como cada um põe em prática os ensinamentos do seu sistema simbólico-religioso. É a forma como cada pessoa vive e expressa a sua religião no dia a dia. A religiosidade, de carácter sincrético, abrange e integra comportamentos, crenças, práticas, atitudes, valores, experiências e sentimentos. Se refere ao grau de aceitação ou ligação que cada indivíduo ou grupo tem face à sua instituição religiosa, nomeadamente, no que diz respeito à frequência em rituais e atividades religiosas cotidianas. A própria vida cotidiana, o trabalho, a família, o sofrimento, a morte, só têm sentido no contexto da cultura e da prática religiosa da própria comunidade. A religiosidade apresenta, na verdade, uma concepção de mundo que nada tem de doutrinal, mas o resultado de uma longa experiência coletiva, no sentido durkheimiano.

Sendo assim, para entender o fenômeno religioso é imprescindível refletir sobre suas formas de manifestação nos seus contextos sociais e culturais específicos, considerando seus aspetos simbólicos e sua exteriorização nas esferas coletivas (sociológicas) e individuais (psicológicas).

Nesse contexto, e agora do ponto de vista psicológico, é pertinente realçar que diferenças no estilo cognitivo, na personalidade ou no tipo de motivação influenciam a forma como a religião é vivida. De acordo com Yoon e Lee (2006), há várias dimensões da religiosidade que podem 
ser analisadas, mas as mais amplamente investigadas são a religiosidade subjetiva (visão que o sujeito tem da sua própria religiosidade, ou seja, o quão religioso se considera), a denominação religiosa (religião praticada pelo indivíduo) e as práticas religiosas cotidianas (número de vezes que uma pessoa vai à igreja e/ou frequenta atividades ou serviços religiosos).

A atitude religiosa inclui as crenças e práticas religiosas, mas também envolve sentimentos positivos e negativos associados a essas crenças (Ferreira \& Neto, 2012; Hill \& Hood, 1999). O indivíduo, por meio da religiosidade, pode atribuir significados aos fatos, compreendendo-os como parte de algo mais amplo, mediante a crença de que nada ocorre ao acaso e acontecimentos da vida são determinados por uma força superior (Rodrigues, 2013). Tais fatos, associados às crenças pessoais, podem levar a um enriquecimento individual, como sabedoria, equilíbrio e maturidade (Araújo et al., 2008). A religiosidade, que envolve sistemas de culto e de doutrina compartilhada dentro de um grupo, pode ter duas orientações, a intrínseca e a extrínseca: na intrínseca, a pessoa internaliza as suas crenças de tal modo que a religião (força maior) faz parte integrante da sua vida diária; na extrínseca, a pessoa utiliza a religião como forma de atingir os seus próprios fins, como encontrar segurança, status social, consolo e interação social e o compromisso com os valores religiosos é mais superficial (Allport \& Ross, 1967). A religiosidade pode, igualmente, seguir duas vertentes: organizada (práticas religiosas públicas na igreja) e não organizada (práticas religiosas privadas, como oração pessoal, meditação, leitura de textos religiosos e da bíblia, audição de música religiosa e visualização de programas religiosos na televisão) (Baker, 2003).

\section{A religiosidade como promotor de funcionamento mental}

Lago-Rizzardi et al. (2010) e Fleury et al. (2018) ressaltam que a religiosidade aparece como primeira ou segunda estratégia de coping em condições de dor, sendo evidenciados resultados fisiológicos significativos como diminuição da queixa de dor, da pressão arterial sistólica, da frequência cardíaca e respiratória. Por intermédio das atividades religiosas, a ativação do córtex pré-frontal sobe consideravelmente, promovendo a elevação dos mediadores envolvidos na dor, como GABA, serotonina e dopamina (Lago-Rizzardi et al., 2010). Para muitos idosos, a religião se torna o principal fator de apoio social. Por meio de instituições religiosas, os idosos socializam, se inserem em grupos e participam em atividades sociais que acontecem com regularidade no contexto das comunidades religiosas. Estudos realizados em Inglaterra e nos Estados Unidos comprovaram que a prática religiosa continuada (maior religiosidade) é um fator relevante na promoção de qualidade de vida da população idosa. A religião fornece um sistema organizado de práticas sociais e de crenças sobre o sentido da vida, dando estrutura e ajudando a julgar o que é certo ou errado. A religiosidade, como prática religiosa cotidiana (como a participação em atividades religiosas), pode proporcionar o suporte e orientação necessários para manter e melhorar o funcionamento mental (Koenig, 2009). No entanto, são necessárias ainda mais pesquisas que procurem entender essa relação entre religiosidade e qualidade de vida, que pressupõe um bom nível de funcionamento mental (Koenig, 2009; Koenig et al., 2012).

O funcionamento mental se refere ao bom funcionamento do cérebro, nomeadamente, às suas funções mentais globais (como consciência, função de orientação, motivação e controle de impulsos) e funções mentais específicas (como atenção, memória, emoção e perceção) (Fisher et al.,2019). Por sua vez, esse proporciona importante informação acerca da forma como as pessoas aprendem a lidar com as diferentes circunstâncias de vida. De acordo com Bixter et al. (2018), preservar o funcionamento mental e cognitivo é reflexo da manutenção de um estilo de vida saudável, ativo e independente. Essa manutenção acontece, por exemplo, por meio do gerenciamento de medicamentos e finanças e aprendizagem de novas habilidades, tendo em consideração que muitas atividades cotidianas exigem processos cognitivos complexos. Desse modo, é vital uma melhor compreensão do efeito protetor que o engajamento social exerce sobre o funcionamento cognitivo.

As práticas religiosas como suporte social, por sua vez, fornecem apoio emocional, principalmente para o idoso que, com o avançar da idade, utilizando cada vez mais a sua religiosidade nas relações sociais, pode obter, deste modo, melhorias na saúde física e mental (Bixter et al., 2018; Faller et al., 2010). A religiosidade pode atuar numa série de contextos ou propósitos, estando ligada a ganhos a nível psíquico, tais como: redução de ansiedade, autocontrole e crescimento pessoal, assim como a busca de significado, conforto e paz (Amorim et al., 2017; Pargament \& Ano, 2004). Segundo Gundlach e Opfinger (2011), os comportamentos religiosos também levam a um sentimento de utilidade e, como mostram Greene e Yoon (2007) e Abdala et al. (2015), o bem-estar aumenta com a prática religiosa do indivíduo, existindo uma ligação entre a felicidade e a frequência de atividades religiosas (Oliveira \& Alves, 2014). Outro ponto relevante que se relaciona com o envelhecimento se prende com a questão das incapacidades, que remete para a aceitação da inevitável mudança, que é diferenciada de idoso para idoso. A esse nível, a religiosidade assume um papel positivo no enfrentar das incapacidades, sendo um importante mecanismo no reforço do bem-estar e do funcionamento mental (Moberg, 2008; Scortegagna et al., 2018).

Nos últimos anos, alguns estudos (e.g., Amorim et al., 2017; Dias \& Pais-Ribeiro, 2018) constataram que a manutenção de um padrão alto de religiosidade e espiritualidade ${ }^{2}$ no processo de envelhecimento origina um maior e melhor equilíbrio mental-psicológico. Os estudos 
mostram ainda que a religiosidade em adultos mais velhos se correlaciona, positivamente, com a frequência e qualidade das interações familiares intergeracionais, assim como proporciona redes de convívio mais alargadas e apoiantes, resultando quase sempre em mudanças positivas ao nível da saúde mental (Pargament \& Ano, 2004; Scortegagna et al., 2018; Wink \& Dillon, 2008). Autores que estudam esta temática (Moreira-Almeida et al., 2006) identificaram 850 artigos sobre vários países - publicados ao longo do século XX e na primeira década do século XXI - que comprovam que indivíduos mais religiosos possuem maior/melhor qualidade de vida e, por conseguinte, apresentam melhores índices de funcionamento mental. Lawton (1982), psicólogo especialista em envelhecimento, foi um dos primeiros autores a trabalhar a questão do estado funcional da pessoa idosa, referenciando-o como a interação entre dois conjuntos de variáveis: as variáveis individuais ou competências (do ponto de vista mais psicológico) e as variáveis ambientais, com a influência exercida pelo meio envolvente (do ponto de vista mais sociológico). As competências individuais incluem a saúde física e mental, capacidades cognitivas, afetividade, qualidade de vida, autoeficácia e controlo de si e do meio. As variáveis ambientais incluem a habitação, o ambiente social e as relações de vizinhança. As relações entre os dois tipos de variáveis determinam o estado funcional de cada indivíduo. Couvreur (2001) refere que as necessidades do ser humano podem sofrer mudanças consoante o contexto em que ele está inserido. Para uma boa qualidade de vida no idoso, é fundamental que se promova um equilíbrio entre os quatro domínios das necessidades fundamentais: físicas, psíquicas, sociais e espirituais (Amorim et al., 2017).

Vejamos agora o caso da religiosidade da sociedade portuguesa. De acordo com o European Social Survey (ESS, 2018), 69,1\% da amostra portuguesa se considera católica, 14\% afirma não ter religião e 3\% de outras religiões. A assistência à missa semanal corresponde a $26,2 \%$ da amostra, prevalecendo a assistência ocasional de 48\%. Em comparação com outros países católicos, apenas a Irlanda e a Polônia apresentam maiores taxas, quer de participação semanal na missa, quer de oração diária. Através de uma análise dos dados quantitativos, carecendo de uma melhor exploração qualitativa, pese ainda o fato de os portugueses relacionarem a fé com aspetos mais mundanos e menos transcendentes, a religiosidade em Portugal é marcada, claramente, por uma elevada confiança na igreja enquanto instituição (Arroyo-Menéndez, 2007). Em 2008, por exemplo, o European Values Survey (ESV, 2015) revelou que $65,3 \%$ da população portuguesa tinha confiança nas igrejas.

O presente trabalho tem como objetivo estudar as relações entre a religiosidade e o funcionamento mental em idosos portugueses, tendo em conta as evidências que a literatura apresenta para a faixa etária em estudo. Vejamos como o trabalho foi elaborado, seguindo uma metodologia quantitativa.

\section{MÉTODO}

\section{Participantes}

A amostra por conveniência estudada é composta por 112 indivíduos, oriundos dos distritos de Aveiro, Coimbra, Porto, Guarda, Leiria, Viseu, Santarém, Lisboa e Castelo Branco. Como critérios de participação, se incluíram a idade (igual ou superior a 60 anos) e compreensão adequada da língua escrita e/ou falada. Dos 112 participantes, 68 são do gênero feminino e 44 do gênero masculino, variando as idades entre 60 e 95 anos $^{3}$, com uma média de 71,4 anos e desvio padrão igual a 8,25 . No que se refere à frequência relativa da variável religião, os dados são apresentados na Tabela 1.

2 Embora não seja uma variável utilizada nesse estudo, é pertinente explicar que, apesar da proximidade, espiritualidade e religiosidade não têm o mesmo significado. Espiritualidade é o modo pelo qual as pessoas entendem e vivem as suas vidas tendo em conta o seu significado e valor últimos. Atualmente, tem-se começado a atribuir maior importância à espiritualidade do indivíduo, sobretudo no que diz respeito à compreensão da forma como as crenças interferem no nível da saúde. Portanto, espiritualidade está vinculada a uma procura pessoal de sentido, com ênfase no aperfeiçoamento do potencial humano, não se limitando, portanto, a qualquer tipo específico de crença ou prática religiosa (Margaça \& Rodrigues, 2019, p. 151).

3 Foram estabelecidos dois grupos de comparação: Grupo 1 - 60 até 70 anos; Grupo 2 - 71 até 95 anos.
Tabela 1

Frequência relativa à variável Religião

\begin{tabular}{lcc}
\hline Religião & Frequência & Percentagem \\
\hline Católica & 96 & 85,7 \\
Evangélica & 13 & 11,6 \\
Sem Religião & 3 & 2,7 \\
Total & 112 & 100 \\
\hline
\end{tabular}

\section{Instrumentos}

Foi elaborado um questionário sociodemográfico com especial incidência na experiência religiosa dos sujeitos, de modo a fornecer um quadro exaustivo das características da amostra sob o ponto de vista da experiência religiosa. Desse fizeram parte, igualmente, questões relativas à escolaridade, agregado familiar, renda mensal e doenças.

Como medida de Religiosidade foi utilizada a 'Age Universal' I/E-R Scale - criada por Gorsuch e McPherson - numa versão portuguesa (ainda em estudo) elaborada por Linares (2012), a Escala de Orientação Religiosa-R ( $\alpha=$ 0,89 ). A origem dessa escala remonta aos conceitos de Allport \& Ross (1967), de religiosidade intrínseca e religiosidade extrínseca. A escala 'Age Universal' I-E Scale surge com 
20 itens (11 orientados para a religiosidade extrínseca e 9 para a religiosidade intrínseca). Após várias alterações, ao longo dos anos, a versão utilizada compreende 14 itens, onde os itens $1,4,5,7,10,12$ e 14 correspondem à escala de religiosidade intrínseca; os itens 6,8 e 9 correspondem à escala de religiosidade extrínseca-pessoal; os itens 2, 11 e 13 à escala de religiosidade extrínseca-social ${ }^{4}$. As respostas são dadas numa escala de Likert de 5 pontos, sendo pontuados da seguinte forma: 1 (discordo totalmente), 2 (discordo em parte), 3 (não tenho a certeza), 4 (concordo em parte) e 5 (concordo totalmente).

O outro instrumento metodológico utilizado foi o MHI-5, uma versão reduzida do Mental Health Inventory (MHI) de cinco itens $(\alpha=0,91)$, que se propõe avaliar a Saúde Mental numa perspetiva que inclui tanto dimensões positivas como negativas. A versão reduzida do MHI-5, no entanto, exprime os mesmos resultados que a versão longa. Os cinco itens representam quatro dimensões de saúde mental: ansiedade, depressão, perda de controle emocional-comportamental e bem-estar psicológico (Pais-Ribeiro, 2001).

\section{Procedimentos}

A recolha da amostra foi efetuada durante os meses de novembro e dezembro de 2013. Foi entregue um consentimento informado, referindo a natureza do estudo e assegurando o anonimato e confidencialidade da apresentação dos dados. As tarefas a realizar envolviam a forma dita "papel e lápis", porém, a maioria dos participantes preferiu que fossem os investigadores a preencher os questionários; por isso, a aplicação foi feita oralmente. Sempre que um item suscitava maiores dúvidas, foi feita uma sucinta explicação do seu conteúdo.

\section{Análise de Dados}

Os dados recolhidos foram analisados com recurso ao software SPSS (Statistical Package for Social Sciences), versão 21 , com a finalidade de suportar a investigação e os estudos efetuados, com base num design crosssectional/transversal de natureza correlacional. As análises preliminares realizadas não revelaram casos extremos nem apontaram para uma violação significativa do pressuposto da normalidade. Adicionalmente à análise da assimetria e da aplicação do teorema do limite central, que permitem a relativização da normalidade no uso de testes paramétricos, o pressuposto da normalidade foi avaliado com recurso à análise das distribuições univariadas normais e da linearidade entre todos os pares de itens (Byrne, 2009). Assim, efetuou-se, em primeiro lugar, o cálculo da consistência interna dos instrumentos, por meio do coeficiente alfa de Cronbach e, seguidamente, se realizaram as estatísticas descritivas para a caracterização da amostra. Para alcançar os objetivos do estudo, foram efetuadas correlações de Spearman para análise da relação entre as dimensões. Foi também realizado o teste t-student (Independent Sample Test) para a comparação da média entre dois grupos e uma ANOVA (Analysis of Variance), a fim de testar diferenças nos grupos estabelecidos, com base numa variável dependente.

\section{RESULTADOS}

Perante à necessidade de analisar a relação entre religiosidade e melhores níveis de funcionamento mental, foi realizada uma análise de correlação. Sendo que esse coeficiente varia entre -1 e 1 , a correlação entre as duas variáveis é moderada, pois os valores de Pearson atingem $r=-0,07$. Porém, não existe relação estatisticamente significativa entre as variáveis religiosidade e melhores níveis de funcionamento mental $(p=0,462)$. Os resultados mostraram, no entanto, que uma das dimensões do

4 A dimensão religiosidade intrínseca inclui os itens relativos a uma religião considerada como uma força motivadora do indivíduo, algo profundamente pessoal. A dimensão religiosidade extrínseca pessoal inclui os itens relativos a uma religião percebida como fonte de conforto e segurança. Por fim, a dimensão religiosidade extrínseca social inclui os itens relativos a uma religião focada nos ganhos sociais. funcionamento mental - o distress ${ }^{5}$ - está correlacionado com uma das dimensões de religiosidade - a religião extrínseca pessoal - , sendo estes valores estatisticamente significativos $(p=0,025)$. O valor da correlação é $r=-0,21$, considerada uma correlação baixa.

Ao realizarmos um $t$ student, temos por objetivo verificar se existe diferença entre os níveis de religiosidade e funcionamento mental entre gêneros. Os resultados mostraram que não existe diferença estatisticamente significativa entre

5 Distress ou "estresse negativo" se diferencia de ansiedade não apenas pelo marco de procedência de ambos os conceitos, mas também pela sua própria natureza. Diferentemente da ansiedade, o distress não supõe a presença de vivência de angústia, mas a produção de um tipo de emoções com expressões negativas bem definidas em nível bioquímico e somático. Um sujeito com estresse negativo pode não ter consciência do seu malestar. 
homens e mulheres no que diz respeito à religiosidade $(p=0,428)$ e ao funcionamento mental $(p=0,497)$. Em relação às três dimensões de religiosidade, também não existem diferenças estatisticamente significativas entre os gêneros: Religião Intrínseca $(p=0,230)$, Religião Extrínseca Pessoal $(p=0,358)$ e Religião Extrínseca Social $(p=$ $0,428)$. Relativamente às duas dimensões de funcionamento mental, também não existem diferenças estatisticamente significativas entre géneros: Bem-Estar Positivo $(p=0,771)$ e Distress $(p=0,527)$.

A fim de verificar se existe diferença entre os níveis de religiosidade e funcionamento mental em relação à idade, foi novamente realizado um $t$ student. Os resultados mostraram que não existe diferença estatisticamente significativa entre idosos mais novos e idosos mais velhos no que diz respeito à religiosidade $(p=0,318)$ e ao funcionamento mental $(p=$ $0,300)$. Em relação às três dimensões de religiosidade, também não existem diferenças estatisticamente significativas entre idades: Religião Intrínseca ( $p=0,290)$, Religião Extrínseca Pessoal $(p=0,376)$ e Religião Extrínseca Social $(p=$ $0,915)$. Relativamente às duas dimensões de funcionamento mental, também não existem diferenças estatisticamente significativas entre os gêneros, sendo Bem-Estar Positivo ( $p=0,336)$ e Distress $(p=0,592)$.

Em relação aos hábitos de oração, não foram encontradas diferenças estatisticamente significativas no que diz respeito à variável global do funcionamento mental $(p=0,692)$, nem às dimensões: Bem-Estar Positivo $(p=0,533)$ e Distress $(p=0,304)$. No entanto, os resultados mostraram haver diferenças estatisticamente significativas tanto na variável global da religiosidade $(p \leq 0,0001)$, como nas suas três dimensões: Religião Intrínseca $(p \leq 0,0001)$, Religião
Extrínseca Pessoal $(p \leq 0,0001)$ e Religião Extrínseca Social $(p=0,037)$.

No que diz respeito às celebrações religiosas (relativamente à participação nestas), não foram encontradas diferenças estatisticamente significativas no que diz respeito à variável global do funcionamento mental $(p=0,398)$, nem às dimensões Bem-Estar Positivo ( $p=0,744)$ e Distress ( $p$ $=0,173)$. Porém, os resultados apresentaram diferenças estatisticamente significativas tanto na variável global da religiosidade $(p \leq 0,0001)$ como nas suas três dimensões: Religião Intrínseca $(p \leq 0,0001)$, Religião Extrínseca Pessoal $(p \leq 0,0001)$ e Religião Extrínseca Social $(p=0,039)$.

Em relação à frequência de participação nas celebrações religiosas, foi realizada uma Anova, que revelou existir diferenças estatisticamente significativas na variável global do funcionamento mental $(p=0,014)$ e na sua dimensão do Bem-Estar Positivo $(p=0,006)$. Se revelaram também diferenças significativas na variável global da religiosidade $(p=0,062)$ e na sua dimensão da Religião Intrínseca $(p=$ $0,013)$. No que diz respeito às outras dimensões, não foram encontradas diferenças estatisticamente significativas.

Por fim, relativamente à religião que dizem praticar, foram encontradas diferenças estatisticamente significativas na variável global do funcionamento mental $(p=0,012)$ e nas suas duas dimensões: Bem-Estar Positivo ( $p \leq$ $0,0001)$ e Distress $(p=0,034)$. Foram também encontradas diferenças estatisticamente significativas na variável global da religiosidade $(p=0,001)$ e em duas das dimensões desta: Religião Intrínseca $(p \leq 0,0001)$ e Religião Extrínseca Pessoal $(p=0,011)$. Apenas não foram encontradas diferenças estatisticamente significativas na dimensão Religião Extrínseca Social.

\section{DISCUSSÃO}

No presente estudo, como se pôde constatar, não foi encontrada uma relação significativa entre religiosidade e funcionamento mental. No entanto, apesar de não previsto nos pressupostos elaborados, foi possível verificar que existem diferenças ao nível do funcionamento mental e de distress entre os idosos que possuem ou não religião, mostrando maiores níveis de distress os que indicaram ter religião. Estes resultados contrariam a informação encontrada no estado da arte (e.g., Lucchetti et al., 2011; Silva et al., 2019). Contudo, estes dados poderão não ser passíveis de generalização, pois uma das limitações do presente estudo se prende com o fato de haver uma grande desigualdade amostral entre os indivíduos religiosos e não religiosos, sendo estes últimos uma minoria.

Também foi possível verificar que existem diferenças significativas no que diz respeito à religião praticada $\mathrm{e}$ o funcionamento mental, mostrando melhores níveis de funcionamento mental os católicos, comparativamente com os evangélicos e os indivíduos sem religião, o que corrobora a literatura (Floriano \& Dalgalarrondo, 2007). Os católicos apresentaram também maiores níveis de bem-estar positivo, tendo sido os evangélicos a apresentar maiores níveis de distress. Segundo Floriano e Dalgalarrondo (2007), tal pode acontecer uma vez que pertencer a uma igreja evangélica implica maior envolvimento religioso e, possivelmente, seguir normas comportamentais mais claras e rígidas, o que se traduziu, no seu estudo, em menor satisfação com suas relações pessoais, com a sua vida sexual e com o apoio social.

No que diz respeito à religiosidade, religião intrínseca e religião extrínseca pessoal, os católicos também apresentaram as maiores pontuações. Esses resultados, no entanto, apresentam também a limitação de haver uma desigualdade entre os números de sujeitos de cada religião, sendo os evangélicos uma minoria.

Outro aspecto a realçar nos resultados alcançados diz respeito à frequência das celebrações religiosas. Os dados encontrados confirmam a literatura existente sobre este tema (Koenig, 2009): os idosos que participam, diariamente, nas celebrações religiosas têm maiores níveis de funcionamento mental e bem-estar positivo (e.g., Abdala et al., 2015; 
Floriano \& Dalgalarrondo, 2007). A comunidade de fé, para muitos idosos, é tida como a rede principal de sociabilidade e, às vezes, a única de apoio social. Esses resultados são corroborados pela literatura especializada, que realça que a participação regular nas celebrações religiosas - o que implica também a participação em atividades sociais - é uma ferramenta importante para uma maior integração social do idoso na comunidade e, consequentemente, na manutenção e melhoria do seu funcionamento mental (Assis et al., 2013; Dias \& Pais-Ribeiro, 2018). Em relação aos resultados das restantes hipóteses, na sua maioria, foram rejeitados. A ausência significativa de relação entre religiosidade e funcionamento mental contraria o que foi apontado por diversos autores na literatura (Dias \& Pais-Ribeiro, 2018; Koenig, 2012). No entanto, esses resultados poderão estar sujeitos a uma outra limitação: a maior parte da amostra foi recolhida junto a idosos que se encontravam na rua, em jardins ou noutros locais públicos, portanto, fora de suas casas. Habitualmente, os idosos com mais vida social, com uma maior integração social são aqueles que possuem melhor funcionamento mental; por isso, é compreensível que, neste grupo específico, não se encontrasse menores níveis de funcionamento mental. Essa limitação poderá também ser referida no caso da comparação entre católicos e evangélicos. Para evitar o enviesamento dos resultados, a amostra deveria alcançar um número equitativo de indivíduos, católicos e evangélicos, o que não aconteceu neste caso. Tal pode ter acontecido, também, devido aos locais públicos onde a amostra foi recolhida: como foi referido, apenas $3 \%$ da população portuguesa se considera de outras religiões. Portanto, menor seria ainda a probabilidade de encontrar, nos locais referidos, membros de outras religiões que não a católica, que é referida como sendo a maioria em Portugal (83\%).

\section{CONSIDERAÇÕES FINAIS}

Em Portugal, as projeções demográficas do INE para 2050 revelam um índice de 243 idosos para cada 100 jovens, o que reflete uma situação preocupante. $\mathrm{O}$ envelhecimento não se circunscreve apenas ao biótico e à passagem do tempo; acima de tudo, é um fenômeno complexo - resultante da interação bio-psico-social-cultural-religiosa e espirituale promotor de mudanças. A dimensão religiosa faz parte da estrutura ontológica do ser humano. O grau de participação ou de adesão a crenças e práticas de uma religião organizada se designa religiosidade e envolve, também, sistemas de culto e de doutrina compartilhada dentro de um grupo.

As conclusões retiradas deste estudo assentam no fato de que, apesar de os resultados não mostrarem uma relação significativa entre religiosidade e funcionamento mental, este acaba por sofrer influências por parte da prática religiosa. Tal foi possível de constatar com o fato de a participação em celebrações religiosas aumentar os níveis de funcionamento mental e bem-estar positivo. Como atestado na literatura especializada, a participação em atividades religiosas permite aos idosos a inserção em grupos e participação em atividades sociais, se formando, assim, uma rede de apoio social e fornecendo qualidade de vida e bem-estar e, por conseguinte, promovendo um melhor funcionamento mental.

A elevada espiritualidade e religiosidade está associada a baixos níveis de ansiedade, a uma adaptação à doença e a uma melhor saúde mental, também influenciando positivamente a capacidade pessoal para participar na promoção da saúde e a sensação de bem-estar. Consequentemente, o elevado envolvimento religioso melhora o funcionamento mental e diminui a procura de cuidados de saúde. Como explicitado nos resultados do estudo, os idosos que participam em celebrações religiosas têm melhores níveis de funcionamento mental, tanto na variável global do funcionamento mental como na sua dimensão do bem-estar positivo, o que vem corroborar os dados da literatura sobre essa temática. $\mathrm{O}$ suporte religioso está associado a melhor saúde física e mental e proporciona integração, interação e suporte social e emocional. É um recurso poderoso, pois ajuda o idoso a regular e a gerir as emoções associadas a acontecimentos negativos de vida, como perdas, declínio e dor.

Para concluir, e como sugestão de pesquisas futuras, consideramos que é importante aprofundar o papel da rede social - que fornece apoio aos idosos - e de que forma a religião-religiosidade pode melhorar e/ou facilitar o estabelecimento desta rede, bem como o seu impacto no funcionamento mental de cada indivíduo. Desse modo, é crucial estabelecer estratégias que permitam evitar o isolamento social dos idosos, a solidão e, com isso, melhorar o funcionamento mental e a qualidade de vida desse importante seguimento da sociedade portuguesa.

\section{REFERÊNCIAS}

Abdala, G., Kimura, M., Duarte, Y., Lebrão, M., \& Santos, B. (2015). Religiosidade e qualidade de vida relacionada à saúde do idoso. Revista de Saúde Pública, 49(11), 1-9. https://doi. org/10.1590/S0034-8910.2015049005416

Allport, G., \& Ross, J. (1967). Personal religious orientation and prejudice. Journal of Personality and Social Psychology, 5, 432-443. https://doi.org/10.1037/h0021212
Amorim, D., Silveira, C., Alves, V., Faleiros, V., \& Vilaça, K. (2017). Associação da religiosidade com a capacidade funcional dos idosos: uma revisão sistemática. Revista Brasilieira de Geriatria \& Gerontologia, 20(5), 727-735. https://doi. org/10.1590/1981-22562017020.170088

Araújo, M., Almeida, M., Cidrack, M., Queiroz, H., Pereira, M., \& Menescal, Z. (2008). O papel da religiosidade na promoção 
da saúde do idoso. Revista Brasileira em Promoção da Saúde, 21(3), 201-207. https://doi.org/10.5020/584

Araújo, F., Pais-Ribeiro, J., Oliveira, A., \& Pinto, C. (2007). Validação do Índice de Barthel numa amostra de idosos não institucionalizados. Qualidade de Vida, 25(2), 59-66.

Arroyo-Menéndez, M. (2007). Religiosidade e valores em Portugal: comparação com a Espanha e a Europa católica. Análise Social, 42(184), 757-787.

Assis, C., Gomes, J. \& Zentarski, L. (2013). Religiosidade e qualidade de vida na terceira idade: Uma revisão bibliográfica a partir da produção científica. REVER - Revista de Estudos da Religião, 13(2), 119-148.

Baker, D. (2003). Studies of inner life: the impact of spirituality on quality of life. Quality of Life Research, 12(1), 51 - 57. https:// doi.org/10.1023/A:1023573421158

Bixter, M., Blocker, K. \& Rogers, W. (2018). Enhancing social engagement of older adults through technology. In R. Pack., \& A. McLaughlin (Eds.) Aging, Technology and Health (pp. 179-214). Academic Press.

Byrne, B. (2009). Structural equation modeling with AMOS Basic concepts, applications, and programming. Routledge Academic.

Chaves, L., \& Gil, C. (2015). Concepções de idosos sobre espiritualidade relacionada ao envelhecimento e qualidade de vida. Ciência \& Saúde Coletiva, 20(12), 3641-3652. https:// doi.org/10.1590/1413-812320152012.19062014

Couvreur, C. (2001). A Qualidade de Vida: arte para viver no século $X X I$. Lusiciência.

Dias, E., \& Pais-Ribeiro, J. (2018). Espiritualidade e qualidade de vida de pessoas idosas: Um estudo relacional. Psicologia, Saúde \& Doenças, 19(3), 591-604. https://doi. org/10.15309/18psd190310.

European Social Survey (2018). European Social Survey Cumulative File, ESS 1-4-8. Data file edition 1.0. Norway: NSD - Norwegian Centre for Research Data.

European Values Study (2015). European Values Study Longitudinal Data File 1981-2008 (EVS 1981-2008). Cologne: GESIS Data Archive.

Faller, J., Melo, W., Versa, G., \& Marcon, S. (2010). Qualidade de vida de idosos cadastrados na estratégia saúde da família de Foz do Iguaçu-PR. Escola Anna Nery Revista de Enfermagem, 14(4), 803-810. https://doi.org/10.1590/S141481452010000400021

Ferreira, A. \& Neto, F. (2012). Religiosidade e bem-estar em idosos portugueses. [Actas] (pp. 3-11) VII Congresso Português de Sociologia, Porto, Portugal.

Fisher, G., Chacon, M. \& Chaffee, D. (2019). Theories of Cognitive Aging and Work. In B. Baltes, C. Rudolph, \& H. Zacher (Eds.), Work Across the Lifespan (pp.17-45). Academic press.

Fleury, L., Gomes, A., Rocha, J., Formiga, N., Souza, M., Marques, S. \& Bernardes, M. (2018). Religiosidade, estratégias de coping e satisfação com a vida: Verificação de um modelo de influência em estudantes universitários. Revista Portuguesa de Enfermagem de Saúde Mental (20), 51-57. https://doi.org/ 10.19131/rpesm.0226

Floriano, P., \& Dalgalarrondo, P. (2007). Saúde mental, qualidade de vida e religião em idosos de um Programa de Saúde da Família. Jornal Brasileiro de Psiquiatria, 56(3), 162-170. https://doi. org/10.1590/S0047-20852007000300002.

Freud, S. (1961). Obsessive actions and religious practices. In. J. Strachey (Ed. e Trans.), The Standard Edition of the Complete Psychological Works of Sigmund Freud (pp. 116127). London: Hogarth Press. (Trabalho original publicado em 1907)

Freud, S. (1929/2008). O mal estar na civilização. (I. C. Silva, Trad.). Relógio D’Água. (Trabalho original publicado em 1929)
Greene, K., \& Yoon, B. (2007). Religiosity, economics and life satisfaction. Review of Social Economy, 62(2), 245-261. https:// doi.org/10.1080/00346760410001684460

Gundlach, E., \& Opfinger, M. (2011). Religiosity as a Determinant of Happiness. GIGA Research Programme: Socio-Economic Challenges in the Context of Globalisation, 163, 1-26.

Hill, P. \& Hood, R. (1999). Measures of Religiosity. Religious Education Press.

Instituto Nacional de Estatística. (2012). Resultados Definitivos Censos 2011. Anuais INE. http://www.ine.pt em 15 de outubro de 2013.

Koenig, H. (2009). Research on religion, spirituality, and mental health: A review. The Canadian Journal of Psychiatry, 54(5), 283-291. https://doi.org/10.1177/070674370905400502

Koenig, H. (2012). Medicine, religion, and health: Where science and spirituality meet. Templeton Press.

Koenig, H., McCullough, M., \& Larson, D. (2012). Handbook of Religion and Health. Oxford University Press.

Lago-Rizzardi, C., Teixeira, M., \& Siqueira, S. (2010). Espiritualidade e religiosidade no enfrentamento da dor. O Mundo da Saúde, 34(4), 483-487. https://doi.org/10.15343/01047809.20104483487

Lawton, M. (1982). Competence, environmental press and adaptation. In M. Powel, P. Windley \& T. Byerts, (Eds), Aging and the environment: Theoretical approaches (pp. 33-59). Springer.

Lewis, C. (1994). Religiosity and obsessionality: The relationship between Freud's "religious practices". The Journal of Psychology, 128(2), 189-196. https://doi.org/10.1080/00223 980.1994.9712723

Linares, R. (2012). Envolvimento Religioso e a Sintomatologia Depressiva em Emigrantes Brasileiros [Tese de Doutorado]. Universidade de Lisboa.

Lucchetti, G., Lucchetti, A., Bassi, R., Nasri, F., \& Nacif, S. (2011). O idoso e sua espiritualidade: Impacto sobre diferentes aspectos do envelhecimento. Revista Brasileira de Geriatria \& Gerontologia, 14(1), 159-167. https://doi.org/10.1590/S180998232011000100016

Margaça, C. \& Rodrigues, D. (2016). Pode a espiritualidade tornar adultos e idosos mais resilientes? Observatório da Religião, $3(2), 148-171$.

Margaça, C., \& Rodrigues, D. (2019). Espiritualidade e resiliência na adultez e velhice: Uma revisão. Fractal: Revista de Psicologia, Niterói, 31(2), 150-157. https://doi.org/10.22409/1984-0292/ v31i2/5690

Moberg, D. (2008). Disabilities, spirituality, and well being in late life: research for study and practice. Journal of Religion, Spirituality \& Being, 20(4), 313-340. https://doi. org/10.1080/15528030802232379

Moreira-Almeida, A., Lotufo-Neto, F., \& Koenig, H. (2006). Religiousness and mental health: a review. Revista Brasileira Psiquiatria, 28(3), 242-250. https://doi.org/10.1590/S151644462006005000006

Oliveira, R., \& Alves, V. (2014). A qualidade de vida dos idosos a partir da influência da religiosidade e da espiritualidade: Cuidados prestados aos idosos institucionalizados em Caetité (BA). Revista Kairós Gerontologia, 17(3), 305-327. https:// doi.org/10.23925/2176-901X.2014v17i3p305-327

Organização Mundial de Saúde (1998). Resolution EB101.R2. Fifty-Second World Health Assembly A52/24. http://apps.who. int/gb/archive/pdf files/WHA52/ew24.pdf

Pais-Ribeiro, J. (2001). Mental Health Inventory: um estudo de adaptação à população portuguesa. Psicologia, Saúde \& Doenças, 2(1), 77-99.

Pargament, K., \& Ano, G. (2004). Empirical advances in the psychology of religion and coping. In K. Warner Schaie, 
N. Krause, \& A. Booth (Eds), Religious influences on health and well-being in the elderly (pp. 114-140). Springer Publishing.

Pedone, M. (2019). Envelhecimento saudável: Uma revisão integrativa. Revista Brasileira de Ciências do Envelhecimento Humano, 16(2), 50-50.

PORDATA (2020). Indicadores de envelhecimento. https://www. pordata.pt/Portugal/Indicadores $+\mathrm{de}+$ envelhecimento-526

Portela, B. (2013). O conceito religião no pensamento de Carl Gustav Jung. Sacrilegens, 10(1), 46-61.

Queiroz, L., \& Debella, M. (2016). Os benefícios da religiosidade na velhice. In J. Sarate (Org.), Impacto Científico e Social na Pesquisa (IX Mostra de iniciação cientifica e extensão comunitária e VIII Mostra de Pesquisa de Pós-Graduação da IMED, pp. 67-73). Editora IMED.

Rodrigues, D. (2013). O Que é Religião: a visão das ciências sociais. Editora Santuário.

Rowe, J. \& Kahn, R. (1998). Successful Aging. Pantheon Books.

Scortegagna, H., Pichler, N., \& Fáccio, L. (2018). Vivência da espiritualidade por idosos institucionalizados. Revista
Brasileira de Geriatria \& Gerontologia, 21(3), 304-311. https://doi.org/10.1590/1981-22562018021.180011.

Silva, G., Reis, D., Miranda, T., Melo, R., Coutinho, M., Paschoal, G., \& Chavez, E. (2019). Coping religioso/espiritual e a angústia espiritual em pessoas com câncer. Revista Brasileira de Enfermagem, 72(6), 1611-1617. https://doi. org/10.1590/0034-7167-2018-0585

Simmel, G. (1889/1997). Essays on Religion. Yale University Press. Xavier, M. (2006). O conceito de religiosidade em C. G. Jung. Psico, 37(2), 183-189.

Weber, M. (1997). Sociología de la religión. ISTMO.

Wink, P., \& Dillon, M. (2008). Religiousness, spirituality, and psychosocial functioning in late adulthood: Findings from a longitudinal study. Psychology of Religion and Spirituality, 1, 102-115. https://doi.org/10.1037/1941-1022.S.1.102

Yoon, D., \& Lee, E. K. (2006). The impact of religiousness, spirituality, and social support on psychological well-being among older adults in rural areas. Journal of Gerontological Social Work, 48(3-4), 281-298. https://doi.org/10.1300/ J083v48n03_01 